\title{
LETTERS
}

\section{Intensive BP Control Falls and Fractures}

\author{
Oscar M. P. Jolobe, MRCP
}

Manchester Medical Society, Manchester, UK.

J Gen Intern Med 30(5):546

DOI: $10.1007 / \mathrm{s} 11606-015-3190-0$

C Society of General Internal Medicine 2015

$\mathrm{I}$ $\mathrm{n}$ the study by Margolis et al., although the adjusted rate of falls did not differ in the intensive and standard groups during the course of antihypertensive therapy, ${ }^{1}$ it is worth noting that no account was taken of whether or not there might be a difference between the two groups in the prevalence of orthostatic hypotension. Orthostatic hypotension is age-related in its prevalence, and is also associated with antihypertensive treatment and diabetes, respectively. ${ }^{2}$ Furthermore, although orthostatic blood pressure responses stabilize within 30 seconds of standing in subjects aged 50-59 years, there is an impairment of blood pressure stabilization with increasing age. ${ }^{3}$ Typical symptoms of orthostatic hypotension may be absent in subjects who have orthostatic hypotension. In a study that enrolled 205 subjects of mean age $71,33 \%$ of the subjects were asymptomatic despite profound falls in blood pressure during the head-up tilt table test. ${ }^{4}$ Accordingly, although the raw rate of falls was comparable in the intensively treated subjects vs, the standard treatment group, ${ }^{1}$ what we need to know is whether or not orthostatic hypotension (and its severity) might have contributed to falls in either group.

Corresponding Author: Oscar M. P. Jolobe, MRCP; Manchester Medical Society, Manchester, UK (e-mail: oscarjolobe@yahoo.co.uk).

\section{REFERENCES}

1. Margolis KL, Palermo L, Vittinghoff E, et al. Intensive blood pressure control, falls, and fractures in patients with type 2 diabetes: the ACCORD Trial. J Gen Intern Med. 2014;29:599-606.

2. Fedowrski A, Stavenow L, Hedblad B, et al. Orthostatic hypotension predicts all-cause mortalityband coronary events in middle-aged individuals (the Malmo Preventive Project). Eur Heart J. 2010;31:8591.

3. Finucane C, O'Connell MDL, Fan CW, et al. Age-related normative changes in phasic orthostatic blood pressure I a large population study. Circulation. 2014;130:1780-9.

4. Arbogast SD, Alshekhlee A, Hussain Z, et al. Hypotension unawareness in profound orthostatic hypotension. Am J Med. 2009; 122:574-80.

Published online February 10, 2015 